\title{
Precursors' Order Effect on the Properties of Sulfurized $\mathrm{Cu}_{2} \mathrm{ZnSnS}_{4}$ Thin Films
}

\author{
P.A. Fernandes ${ }^{1,2, *}$, P.M.P. Salomé ${ }^{1, a}$, A.F. da Cunha ${ }^{1, b}$
}

${ }^{1}$ I3N- Departamento de Física, Universidade de Aveiro, Campus Universitário de Santiago, 3810-193 Aveiro, Portugal

${ }^{2}$ Departamento de Física, Instituto Superior de Engenharia do Porto, Instituto Politécnico do Porto, Rua Dr. António Bernardino de Almeida, 431, 4200-072 Porto, Portugal

a psalome@ua.pt

bantonio.cunha@ua.pt

*Corresponding author, pafernandes@ua.pt

\section{Abstract:}

A dc magnetron sputtering based method to grow high quality $\mathrm{Cu}_{2} \mathrm{ZnSnS}_{4}$ (CZTS) thin films, to be used as absorber layer in solar cells, is being developed. This method combines dc sputtering of metallic precursors with sulfurization in $\mathrm{S}$ vapour and with post growth KCN treatment for removal of possible undesired $\mathrm{Cu}_{2-\mathrm{x}} \mathrm{S}$ phases. In this work we report the results of a study of the effects of changing the precursors' deposition order on the final CZTS films' morphological and structural properties. The effect of KCN treatment on the optical properties was also analysed through diffuse reflectance measurements. Morphological, compositional and structural analyses of the various stages of the growth have been performed using stylus profilometry, SEM/EDS analysis, XRD and Raman Spectroscopy. Diffuse reflectance studies have been done in order to estimate band gap energy of the CZTS films.

We tested two different deposition orders for the copper precursor, namely: $\mathrm{Mo} / \mathrm{Zn} / \mathrm{Cu} / \mathrm{Sn}$ and $\mathrm{Mo} / \mathrm{Zn} / \mathrm{Sn} / \mathrm{Cu}$.

The stylus profilometry analysis shows high average surface roughness in the ranges $300 \mathrm{~nm}$ to $550 \mathrm{~nm}$ and $230 \mathrm{~nm}$ to $250 \mathrm{~nm}$ before and after KCN treatment, respectively. All XRD spectra show preferential growth orientation along (112) at $28.45^{\circ}$. Raman spectroscopy shows main peaks at $338 \mathrm{~cm}^{-1}$ and $287 \mathrm{~cm}^{-1}$ which are attributed to $\mathrm{Cu}_{2} \mathrm{ZnSnS}_{4}$. These measurements also confirm the effectiveness of $\mathrm{KCN}$ treatment in removing $\mathrm{Cu}_{2-\mathrm{x}} \mathrm{S}$ phases. From the analysis of the diffuse reflectance measurements the band gap energy for both precursors' sequences is estimated to be close to $1.43 \mathrm{eV}$. The KCN treated films show a better defined absorption edge, however, the band gap values are not significantly affected. Hot Point Probe measurements confirmed that CZTS had p-type semiconductor behaviour and CV analysis were used to estimate the majority carrier density giving a value of $3.3 \times 10^{18} \mathrm{~cm}^{-3}$. 
Keywords: $\mathrm{Cu}_{2} \mathrm{ZnSnS}_{4}$, CZTS, absorber, sulfurization, thin film, solar cell, KCN

PACS 68.55.-a, 78.55.Hx, 81.15.-z, 84.60.Jt

Submitted to: Semiconductor Science and Technology

\section{Introduction}

In order to avoid the problems related with $\mathrm{CuIn}_{1-\mathrm{x}} \mathrm{Ga}_{\mathrm{x}} \mathrm{Se}_{2}$ (CIGS) like the use of the rare elements In, Ga and toxic ones such as Se, some research groups have turned their attention to alternative absorber compounds with similar properties. With an absorption coefficient of $10^{4}$ $\mathrm{cm}^{-1}$ and band gap energy close to $1.45 \mathrm{eV}$ [1], the quaternary compound, $\mathrm{Cu}_{2} \mathrm{ZnSnS}_{4}$ (CZTS), shows properties that make it a good candidate to replace CIGS.

Several research groups are developing methods to grow this type of absorber layer. The use of vacuum growth techniques such as thermal and e-beam evaporation were successfully used by T. Friedlmeier et al [2] and H. Katagiri et al [3]. These methods used a post sulfurization process for CZTS formation. The co-evaporation method was also used by $\mathrm{T}$. Tanaka et al [4]. Multi-stage evaporation was tested using different types of precursors by A. Weber et al [5]. Sputtering methods were applied by K. Jimbo et al [6] using RF co-sputtering of binary compounds. Using an alternative approach, mainly for the precursor's deposition, non vacuum methods have also been tested. Soft-chemistry methods and sol-gel deposited precursors with post sulfurization processing was tested by T. Todorov et al [7] and K. Tanaka et al [8], respectively. Spray-pyrolsys is among the most tested techniques, namely by $\mathrm{N}$. Nakayama et al [9] and N. Kamoun et al [10]. Several variants of precursor's electrodeposition with sulphur post treatment have been tested by R. Shurr et al [11] and J. Scragg et al [12].

So far, the best result in solar cell efficiency, 6.7\%, was attained by H. Katagiri et al [13] using co-sputtering of elemental and sulphide compounds precursors, a $\mathrm{H}_{2} \mathrm{~S}$-based sulfurization process and post deionised water soaking treatment that had the effect of eliminating metal oxides.

In this work we describe the effects on the CZTS properties of changing the order of the $\mathrm{Cu}$ precursor in our 2-step method, described elsewhere [14]. The CZTS films were subjected to a KCN treatment and its effect was also analysed. The precursor order starting with $\mathrm{Cu}$ is not presented in this work, because this sequence was already studied in our previous work [14]. This work aims at overcoming problems like the loss of $\mathrm{Zn}$ and Sn observed in our previous work with $\mathrm{Mo} / \mathrm{Cu} / \mathrm{Zn} / \mathrm{Sn}$ precursors. 
The first part of the growth method is the sequential deposition of the metallic precursors and the second part refers to the crystal formation by annealing the precursors in a sulphur vapour atmosphere. As shown in previous works, [5, 14], the thermodynamic behaviour of the CZTS growth goes through several stages towards its final quaternary form. Because of its complexity and some unclear formation dynamics, unwanted binary and ternary compounds persist after the procedure reaches the end. A solution to the elimination of binary copper based compounds is the use of a KCN chemical treatment.

\section{Experimental details}

\subsection{Sample preparation}

As mentioned before the work presented here is based on the 2-step CZTS growth method [14]. The soda lime glass (SLG) substrates were cleaned in an ultrasound bath successively in acetone/alcohol/deionised water and finally dried using a $\mathrm{N}_{2}$ gas flux. Next, the deposition of Mo back contact was performed by dc magnetron sputtering from a Mo target with purity $3 \mathrm{~N}$ and following the recipe developed by Scofield et al [15]. Then, the metallic precursors were deposited sequentially using dc magnetron sputtering. Although, the sputtering conditions for the individual metallic precursors were maintained as in [14], some variations were tested, like their deposition order. The sequence variable was the $\mathrm{Cu}$ position. As is well known; this metal presents a higher mobility than $\mathrm{Zn}$ and Sn. Two sequences were tested, namely: $\mathrm{Mo} / \mathrm{Zn} / \mathrm{Cu} / \mathrm{Sn}$ and $\mathrm{Mo} / \mathrm{Zn} / \mathrm{Sn} / \mathrm{Cu}$. All depositions were done under an Ar atmosphere, an operating pressure of $2 \times 10^{-3} \mathrm{mbar}$ and power densities of $0.16 \mathrm{Wcm}^{-2}, 0.38 \mathrm{Wcm}^{-2}, 0.11$ $\mathrm{Wcm}^{-2}$ for $\mathrm{Cu}, \mathrm{Zn}$ and $\mathrm{Sn}$, respectively. The purity of the targets was $5 \mathrm{~N}$ for $\mathrm{Cu}$ and $4 \mathrm{~N}$ for both Zn and Sn. Initial thickness' estimation was done based on element molecular weight and bulk densities. In situ thickness’ monitoring was performed with a quartz crystal monitor.

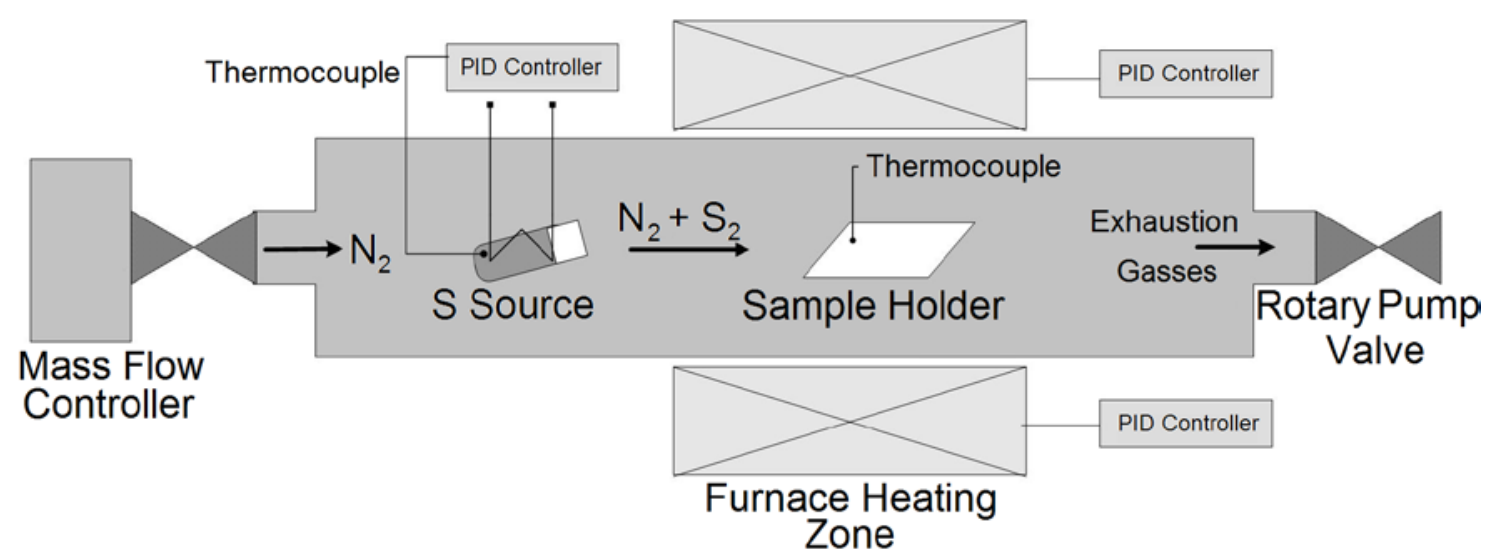

Figure 1. Schematic representation of the sulfurization furnace. 
Figure 1 shows a sketch of the furnace used for the sulfurization process. The CZTS formation was performed in a tubular furnace in a $\mathrm{N}_{2}+\mathrm{S}_{2}$ vapour atmosphere at a constant working pressure of $5.6 \times 10^{-1} \mathrm{mbar}$ and a $\mathrm{N}_{2}$ flow rate of $40 \mathrm{ml} / \mathrm{min}$. The sulphur pellets with purity $5 \mathrm{~N}$, were evaporated at $130{ }^{\circ} \mathrm{C}$ in a temperature controlled quartz tube source. The furnace temperature increases at $10{ }^{\circ} \mathrm{C} / \mathrm{min}$ to a maximum temperature of $525^{\circ} \mathrm{C}$. This temperature was kept constant during $10 \mathrm{~min}$ and then the system was left to cool down naturally.

In order to eliminate unwanted phases that form during the CZTS crystallization process, a KCN chemical treatment was applied to the samples. For this procedure a solution of $\mathrm{KCN}$ at $10 \% \mathrm{w} / \mathrm{w}$ was prepared. The samples were, sequentially, submitted to the KCN bath, a solution of alcohol/deionised water at $50 \% \mathrm{vol} / \mathrm{vol}$ and finally deionised water. Each step had a duration of 2 min. Finally, all samples were dried with a $\mathrm{N}_{2}$ gas flux.

\subsection{Sample characterization}

A Dektak 150 step profiler was used to measure the thickness of individual metallic precursors, the final CZTS layer thickness and its average roughness. In situ thickness measurement was done using a quartz crystal monitor. X-ray diffraction analysis was performed with a PHILIPS PW 3710 system equipped with a $\mathrm{Cu}-\mathrm{K}_{\alpha}$ source (wavelength $\lambda=1.54060 \AA$ ) and the generator settings were 50mA, 40kV. A Hitachi S4100 SEM and a Rontec EDS with setting parameters of $25 \mathrm{kV}$ and $10 \mu \mathrm{A}$ were used for morphological and compositional analysis. Raman scattering measurements have been performed in the backscattering configuration and the excitation laser line used was $514.5 \mathrm{~nm}$. The Jobin-Yvon T64000 Raman spectrometer was equipped with an Olympus microscope with a 100x magnification lens. It focused the laser beam down to a spot size of $1 \mu \mathrm{m}$ in diameter. Diffuse reflectivity measurements were done using a Shimadzu UV3600 spectrophotometer equipped with an integrating sphere. Electrical characterization was performed using a hot point probe device and $\mathrm{C}-\mathrm{V}$ measurements.

\section{Results and Discussion}

Table 1 presents the atomic concentration of the precursors, sulfurized and KCN treated samples. No atomic concentration is presented for Mo and S due to the fact that these elements have coincident EDS peaks.

Table 1. Elemental composition for the precursors, sulfurized and KCN treated samples.

\begin{tabular}{lccc|ccc} 
& \multicolumn{3}{c|}{$\mathrm{Mo} / \mathrm{Zn} / \mathrm{Sn} / \mathrm{Cu}$} & \multicolumn{3}{c}{$\mathrm{Mo} / \mathrm{Zn} / \mathrm{Cu} / \mathrm{Sn}$} \\
\hline & precursors & sulfurized & KCN & Precursors & sulfurized & KCN \\
\hline [Cu] (\%) & 36.4 & 21.2 & 15.7 & 38.1 & 21.5 & 10.5 \\
{$[\mathrm{Zn}$ ] (\%) } & 20.9 & 13.3 & 13.9 & 18.7 & 15.3 & 16.9 \\
[Sn] (\%) & 17.1 & 11.2 & 11.5 & 18.6 & 14.4 & 8.3 \\
\hline
\end{tabular}


Figure 2 shows the metal concentration ratios of the precursors, after the sulfurization process and after the KCN treatment, for the two precursor sequences. The concentrations were measured by EDS. As shown in a previous work [14], the sulfurization process performed under vacuum conditions causes losses of $\mathrm{Zn}$ in the elemental form and $\mathrm{Sn}$ in the sulphide compound form. Both studied precursor sequences showed a decrease in the ratios $[\mathrm{Cu}] /[\mathrm{Zn}]$ and $[\mathrm{Cu}] /[\mathrm{Sn}]$ after sulfurization. These lower ratios may be explained not by the loss of $\mathrm{Cu}$ but by its aggregation in the form of large $\mathrm{Cu}_{2-\mathrm{x}} \mathrm{S}$ crystallites at the top surface of the CZTS layer. The reported losses of $\mathrm{Zn}$ and $\mathrm{Sn}$ seem to be hidden by this effect. The segregation of $\mathrm{Cu}$ sulphide located at the surface of the layer causes concentration deviations in the overall sample results. As expected, after the KCN chemical treatment, the Cu concentration decreased significantly. The final CZTS layers present a $\mathrm{Cu}$ poor composition ranging from 0.4 to 0.7 for the $[\mathrm{Cu}] /([\mathrm{Zn}]+[\mathrm{Sn}])$ ratio. Notice that the two sequences presented an almost stoichiometric initial composition. Opposite behaviour is observed for the $[\mathrm{Zn}] /[\mathrm{Sn}]$ ratio in the case of $\mathrm{Mo} / \mathrm{Zn} / \mathrm{Sn} / \mathrm{Cu}$ and $\mathrm{Mo} / \mathrm{Zn} / \mathrm{Cu} / \mathrm{Sn}$ precursors. In the first case, there is a slight decrease of the $[\mathrm{Zn}] /[\mathrm{Sn}]$ ratio from the precursors to the sulfurized film which can be explained by a higher evaporation rate of $\mathrm{Zn}$ than that of SnS. In the second case there is a slight increase in the $[\mathrm{Zn}] /[\mathrm{Sn}]$ ratio which is explained by the fact that the $\mathrm{Sn}$ is initially on top and hence can form $\mathrm{SnS}$ more easily than in the first precursor leading to a faster loss of Sn than $\mathrm{Zn}$. In the second case the loss of $\mathrm{Zn}$ is further prevented by the middle layer of $\mathrm{Cu}$. The KCN treatment further enhances this differing behaviour. While in the case of the Mo/Zn/Sn/Cu precursor the KCN treatment of the sulfurized film produced no significant change in the $[\mathrm{Zn}] /[\mathrm{Sn}]$ ratio, in the case of the $\mathrm{Mo} / \mathrm{Zn} / \mathrm{Cu} / \mathrm{Sn}$ precursor the increase in the $[\mathrm{Zn}] /[\mathrm{Sn}]$ ratio is unexpected and large. This is an anomalous result which can only be understood if the KCN treatment also removes SnS. The clarification of the latter possibility requires further studies.
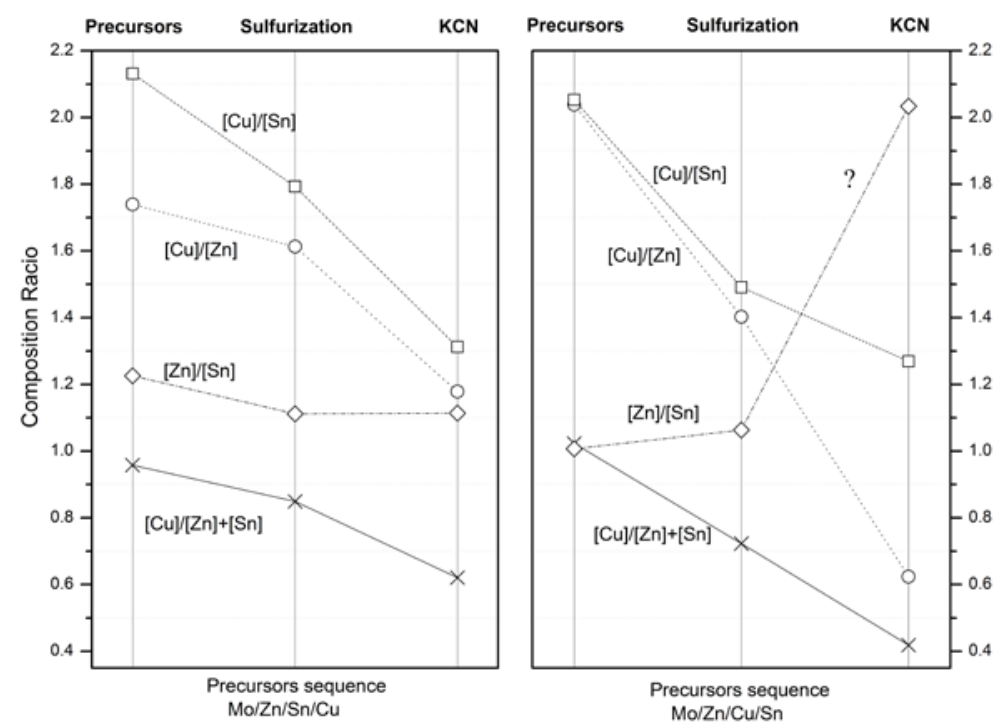
Figure 2. Concentration ratios for metallic precursors, sulfurized layer and after KCN treatment.

The results of stylus profilometry are presented in figure 3. As shown, both thickness and roughness follows identical patterns for the two tested precursor sequences. Despite the pattern similarity and identical final results for both thickness and roughness, these parameters differ substantially for the sulfurized samples. This can be explained by the formation of large $\mathrm{Cu}_{2-\mathrm{x}} \mathrm{S}$ crystallites at the top of the layer. Another significant result is the high roughness value presented for the two precursor's sequences.
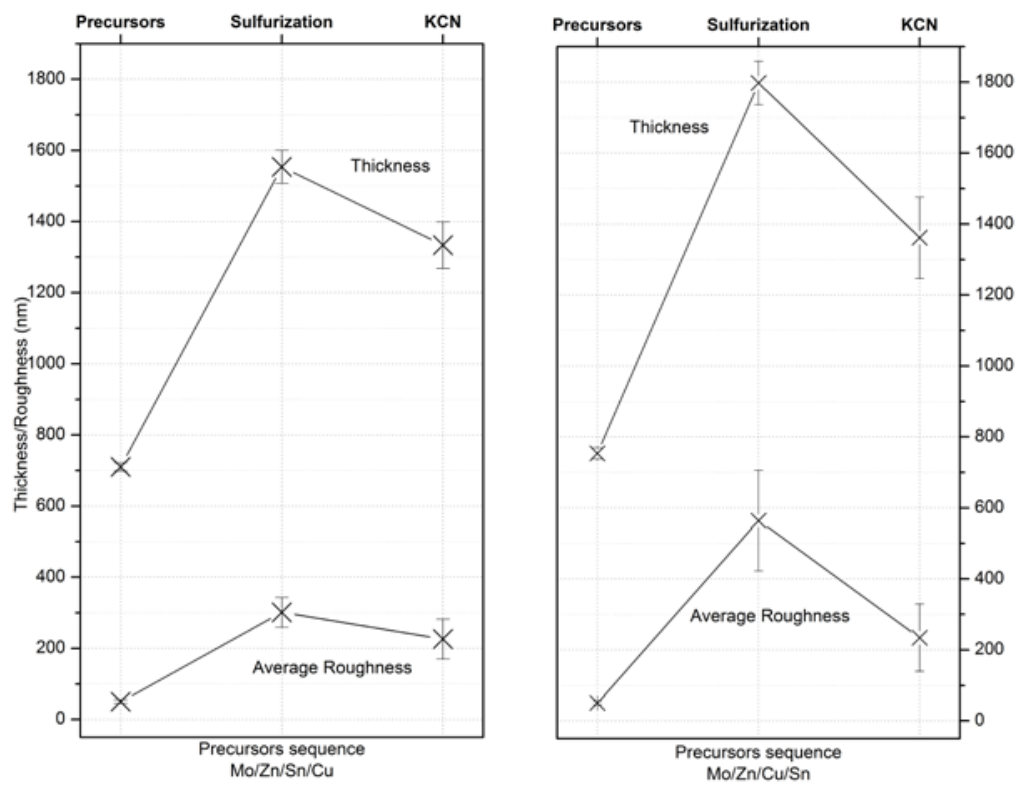

Figure 3. Thickness and roughness results for metallic precursors, sulfurized layer and after KCN treatment.

Figure 4 shows the X-ray diffraction spectra for the samples with different precursor's order. As expected, the two patterns are similar, but for the sample with the precursor order $\mathrm{Mo} / \mathrm{Zn} / \mathrm{Sn} / \mathrm{Cu}$ the peaks have a higher intensity, and it presents more visible peaks than the other studied case. This is attributed to a better crystal quality. This is corroborated by the FWHM and crystallite sizes, presented in table 2. The FWHM value for $\mathrm{Mo} / \mathrm{Zn} / \mathrm{Sn} / \mathrm{Cu}$ order is lower than for $\mathrm{Mo} / \mathrm{Zn} / \mathrm{Cu} / \mathrm{Sn}$. The crystallite size computed using the Scherrer's equation [16] shows a value of approximately $300 \mathrm{~nm}$ for the best case.

Table 2. Full Width Half Maximum for main XRD peak, orientation plane (112). Crystallite size estimation using Scherrer’s equation for the two precursor sequences. 


\begin{tabular}{ccc}
\hline FWHM (degree) & 0.145 & 0.167 \\
\hline Crystallite size (nm) & 300 & 210 \\
\hline
\end{tabular}

The effect of the KCN treatment is also shown in figure 4. It can be seen that the removal of the $\mathrm{Cu}_{2-\mathrm{x}} \mathrm{S}$ phases is effective given the absence of all related peaks in the XRD spectra.
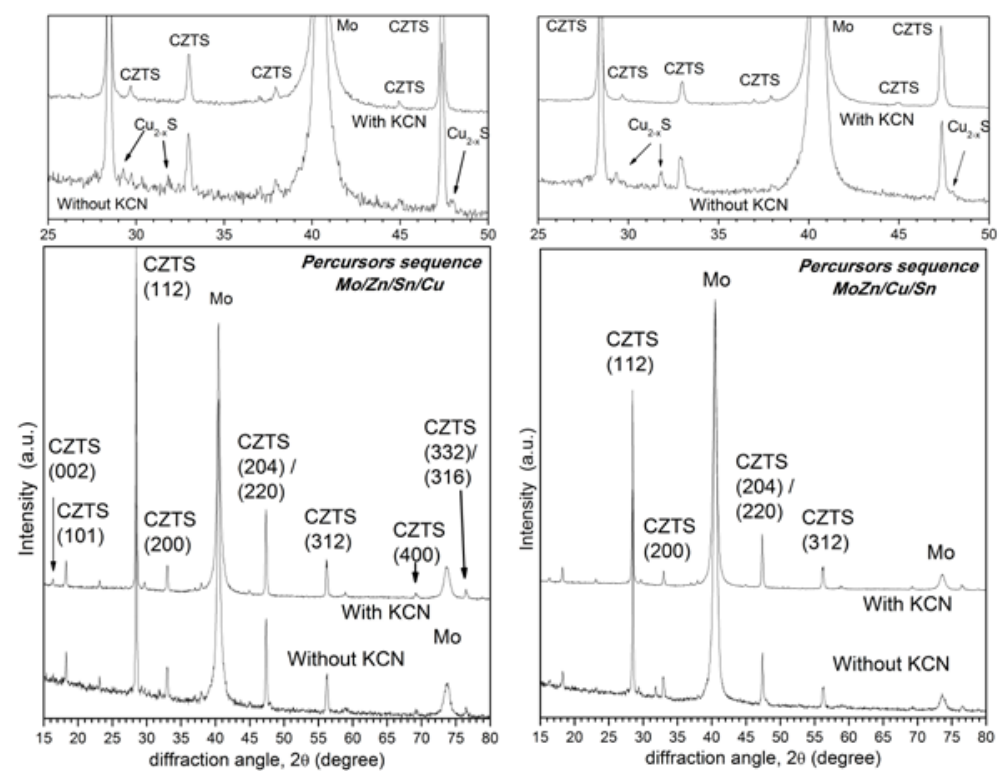

Figure 4. XRD spectra for the tested precursor sequences and the results of the KCN treatment.

Table 3 shows the comparison between the intensity of reference powder peaks, ICDD ref 04-005-0388, and the sample peaks. The results indicate that the preferential growth orientation plane is (112), with a diffraction angle, $2 \theta$, equal to $28.46^{\circ}$.

Table 3. Peaks comparison for reference powder and KCN treated samples.

\begin{tabular}{|c|c|c|c|c|}
\hline \multicolumn{5}{|c|}{ ICDD - ref 04-005-0388 } \\
\hline $2 \theta$ & Rel Int(\%) & h k l & 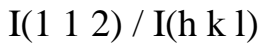 & \\
\hline 28.44 & 99.9 & 112 & 1.00 & \\
\hline 32.93 & 9.0 & $200 / 004$ & 11.10 & \\
\hline 47.33 & 38.3 & 204 & 2.61 & \\
\hline 56.09 & 20.9 & $312 / 116$ & 4.78 & \\
\hline 76.41 & 6.3 & 332 & 15.86 & \\
\hline \multicolumn{5}{|c|}{$\mathrm{Mo} / \mathrm{Zn} / \mathrm{Sn} / \mathrm{Cu}$} \\
\hline $2 \theta$ & Rel Int (\%) & h k l & 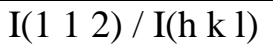 & $\Delta$ \\
\hline 28.47 & 100.00 & 112 & 1.00 & 0.00 \\
\hline 32.99 & 7.92 & $200 / 004$ & 12.63 & 1.53 \\
\hline 47.34 & 24.28 & 204 & 4.12 & 1.51 \\
\hline 56.11 & 9.92 & $312 / 116$ & 10.08 & 5.30 \\
\hline 76.43 & 2.02 & 332 & 49.50 & 33.65 \\
\hline \multicolumn{5}{|c|}{$\mathrm{Mo} / \mathrm{Zn} / \mathrm{Cu} / \mathrm{Sn}$} \\
\hline $2 \theta$ & Rel Int (\%) & $\mathrm{h} \mathrm{k} \mathrm{l}$ & (11 2) / I(h k l) & $\Delta$ \\
\hline 28.46 & 68.06 & 112 & 1.00 & 0.00 \\
\hline
\end{tabular}




\begin{tabular}{rrcrrr}
32.98 & 4.84 & $200 / 004$ & 14.06 & 2.96 \\
47.32 & 17.42 & 204 & 3.91 & 1.30 \\
56.10 & 7.49 & $312 / 116$ & 9.09 & 4.31 \\
76.42 & 1.61 & 332 & 42.27 & 26.42 \\
\hline
\end{tabular}

The structural properties of the CZTS films were further analysed by Raman scattering and the results are shown in figure 5 . These results show that, for CZTS crystal formation, there are no substantial differences in changing the order of the metallic precursors. All show the main CZTS peaks at $338 \mathrm{~cm}^{-1}, 287 \mathrm{~cm}^{-1}$ and $368 \mathrm{~cm}^{-1}$ [14,17]. A more detailed analysis of the main Raman peaks indicates that FWHM values are lower for $\mathrm{Mo} / \mathrm{Zn} / \mathrm{Sn} / \mathrm{Cu}, 3.5 \mathrm{~cm}^{-1}$ than for the configuration $\mathrm{Mo} / \mathrm{Zn} / \mathrm{Cu} / \mathrm{Sn}$ where the $\mathrm{FWHM}$ is $4.0 \mathrm{~cm}^{-1}$. So, these results, again, indicate that when $\mathrm{Cu}$ is the last precursor deposited, in the sequences tested, the absorber layer presents a higher crystal quality.

The KCN treatment effect on the samples is also presented in the figure 5. This procedure, clearly, eliminates $\mathrm{Cu}_{2-\mathrm{x}} \mathrm{S}$ crystallites, from the absorber layers. The evidence resides in the fact that after KCN treatment the Raman peak at $475 \mathrm{~cm}^{-1}$, corresponding to $\mathrm{Cu}_{2-\mathrm{x}} \mathrm{S}$, is absent [18].

It must be noticed that characterization with micro-Raman spectroscopy must be carried out with caution due to limited penetration depth of the radiation, especially with high absorption materials like CZTS. In this work, we estimate that the penetration depth is close to $500 \mathrm{~nm}$, considering an absorption coefficient of $10^{4} \mathrm{~cm}^{-1}$ and a radiation wavelength of 514.5 $\mathrm{nm}[19]$.

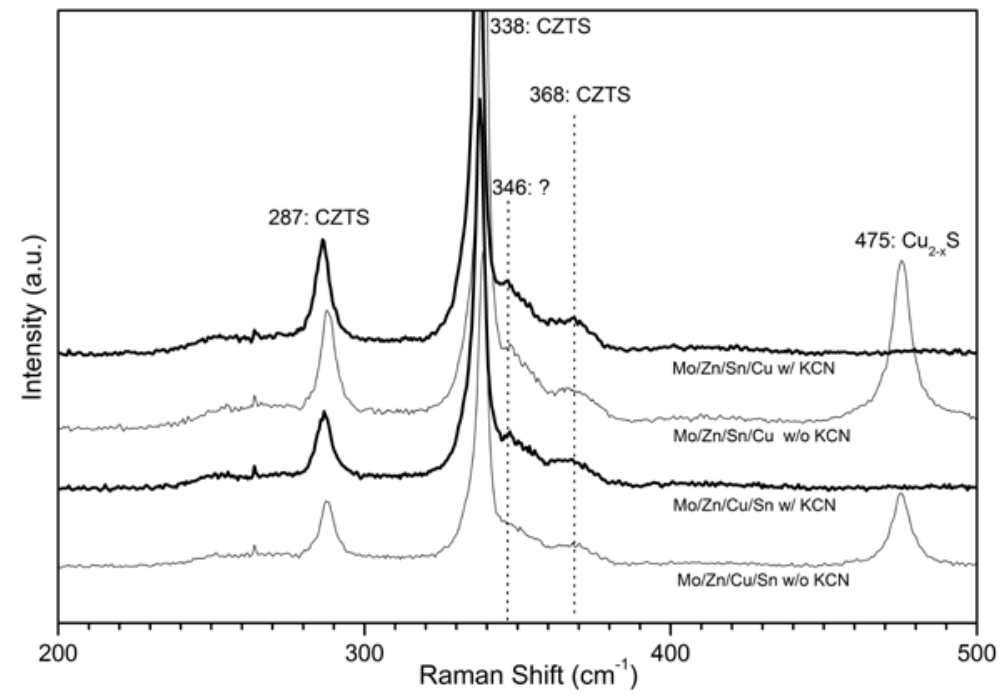

Figure 5. Raman scattering results for the samples with different precursor's sequence. The results, for the same samples after the KCN treatment, are also presented.

The optical properties of the CZTS films were studied through diffuse reflectance measurements and the results are presented in figure 6. The graphs show the diffuse reflectance for the two studied precursor sequences with and without the KCN treatment. The elimination 
of spurious $\mathrm{Cu}_{2-\mathrm{x}} \mathrm{S}$ phases from the CZTS layer has the effect of increasing the diffuse reflectance's slope for wavelengths ranging from $700 \mathrm{~nm}$ to $900 \mathrm{~nm}$. Therefore, a better defined absorption edge is obtained with the referred chemical treatment.
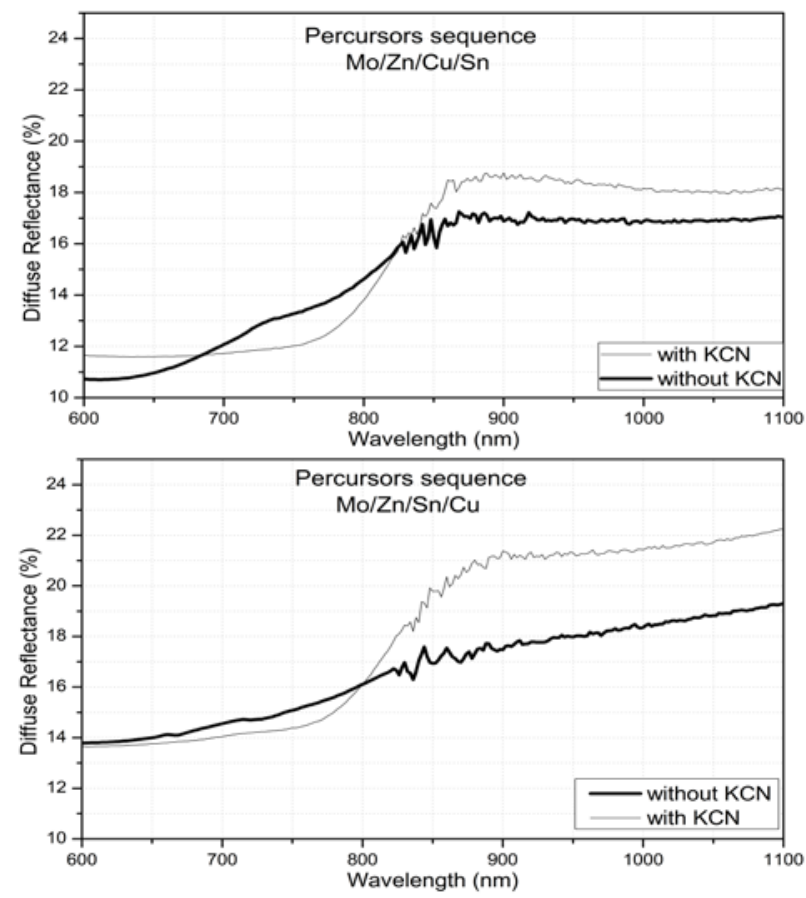

Figure 6. Diffuse reflectance results for the two types of precursor's deposition order with and without the KCN treatment.

Based on the previous results the band gap energy was calculated using the method presented by K. Shankar et al [20]. The figure 7 presents the results of the absorbance versus photon energy for band gap energy estimation, $E_{\text {gap }}$. For the calculation of the absorbance the following relation was used,

$$
A b s=R_{\max }-R_{\lambda}
$$

where $R_{\max }$ is the local maximum value for the diffuse reflectance and $R_{\lambda}$ is the diffuse reflectance for the studied spectral zone. The estimation of the band gap energy is done by extrapolating the tangent line of the absorbance to the zero line.

The results for the band gap calculation show values for the two precursor configurations, between $1.43 \mathrm{eV}$ and $1.45 \mathrm{eV}$. It seems that the $\mathrm{KCN}$ treatment has the effect of lowering slightly these values to $1.41 \mathrm{eV}$ and $1.43 \mathrm{eV}$. Despite the fact that these differences are smaller than the calculus accuracy, the shift seems clear. The explanation for this effect may be related to the better defined absorption edge. In addition, it can be observed in the graphs corresponding to the absorbance without KCN treatment that a secondary slope can be drawn, at an inflexion point near $1.7 \mathrm{eV}$. This can be attributed to binary sulphides, like $\mathrm{Cu}_{2-\mathrm{x}} \mathrm{S}$ [21]. Note that this property is not present in the samples with the KCN treatment. 

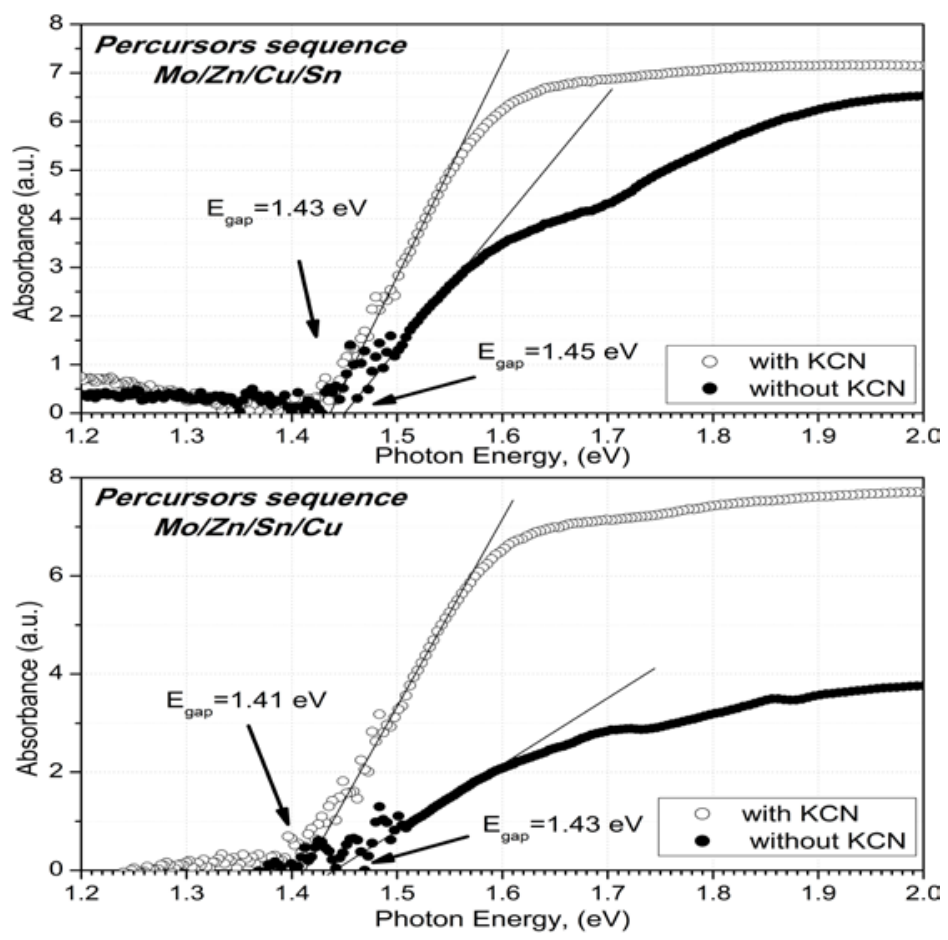

Figure 7. Absorbance versus photon energy for the studied cases. Band gap energy estimation was done using the method described by K. Shankar et al [20].

The morphological analysis of the referred set of samples is presented next. In figure 8 we show the SEM micrographs of the film's surface for the samples as-deposited and after KCN treatment. As expected, in both as-deposited samples, sparsely distributed $\mathrm{Cu}_{2-\mathrm{x}} \mathrm{S}$ crystallites can be seen. These crystallites are clearly identifiable as the faceted grains present. Large areas with rounded dark zones are visible in these two samples with and without KCN treatment. Detailed EDS and Raman analysis of those areas confirmed that in these the elemental composition is close to stoichiometric CZTS. As expected, when comparing the micrographs of the KCN treated samples with those without the treatment it can be seen that the $\mathrm{Cu}_{2-\mathrm{x}} \mathrm{S}$ crystallites were removed. As a consequence voids appear after this procedure, especially for the samples with the $\mathrm{Mo} / \mathrm{Zn} / \mathrm{Cu} / \mathrm{Sn}$ sequence. A possible explanation to this fact is that some samples seem to have small $\mathrm{Cu}_{2-\mathrm{x}} \mathrm{S}$ crystallites encrusted in CZTS forming holes after its removal. These micrographs confirmed the results shown in the figure 3. The films' roughness is considerable, which tend to degrade the absorber layer quality. 


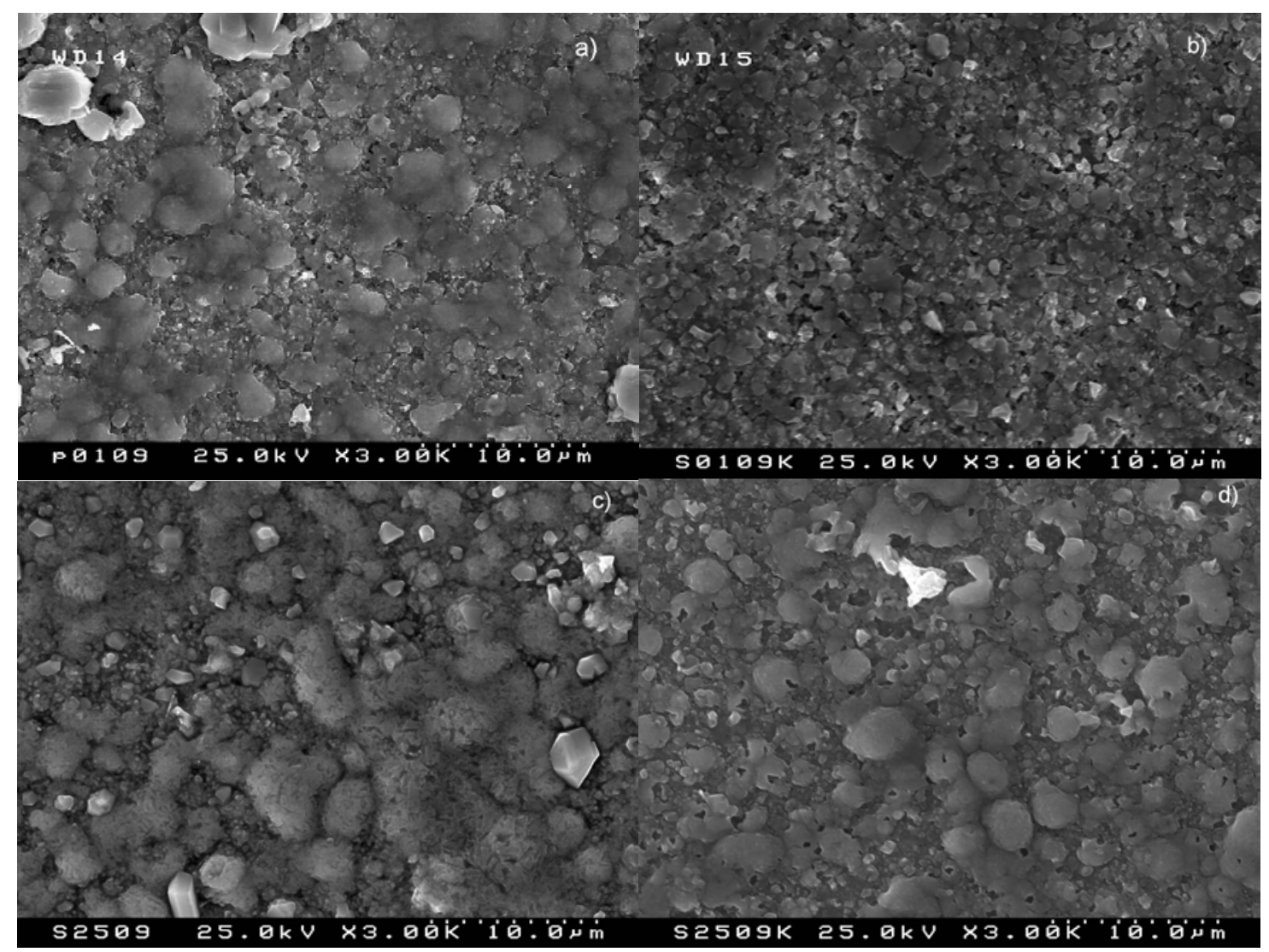

Figure 8. Surface SEM micrographs for CZTS films: a) $\mathrm{Mo} / \mathrm{Zn} / \mathrm{Cu} / \mathrm{Sn}$ precursor sequence without $\mathrm{KCN}$ treatment; b) $\mathrm{Mo} / \mathrm{Zn} / \mathrm{Cu} / \mathrm{Sn}$ precursor sequence with $\mathrm{KCN}$ treatment; c) $\mathrm{Mo} / \mathrm{Zn} / \mathrm{Sn} / \mathrm{Cu}$ precursor sequence without $\mathrm{KCN}$ treatment; d) Mo/Zn/Sn/Cu precursor sequence with KCN treatment.

Electrical measurements using Hot Point Probe were done confirming that both KCN treated sample had p-type semiconductor behaviour. C-V measurements were performed on samples with both precursors' order. The results were analysed considering the relative dielectric constant, $\varepsilon_{\mathrm{r}}$, to be equal to 10 , the measured device area of $0.25 \times 10^{-4} \mathrm{~m}^{2}$ and the signal frequency used of $75 \mathrm{kHz}$. Estimated majority carrier density of the order of $3.3 \times 10^{18} \mathrm{~cm}^{-3}$ were obtained [22]. This result is in agreement with those obtained by T. Tanaka et al. [23].

\section{Conclusions}

This work shows that for the approach followed the best precursor sequence for the $\mathrm{Cu}_{2} \mathrm{ZnSnS}_{4}$ (CZTS) growth is the $\mathrm{Mo} / \mathrm{Zn} / \mathrm{Sn} / \mathrm{Cu}$. The EDS results show that, for the sulfurization conditions used in this work, the $\mathrm{Cu}$ layer on top reduces the loss of $\mathrm{Zn}$ and $\mathrm{Sn}$. This allows for a better composition control of the CZTS. The XRD and Raman spectroscopy also show a better crystal quality of the CZTS films resulting from the $\mathrm{Mo} / \mathrm{Zn} / \mathrm{Sn} / \mathrm{Cu}$ precursors. 
Hot Point Probe measurements confirmed that the obtained CZTS is a p-type semiconductor and $\mathrm{C}-\mathrm{V}$ analysis showed that the majority carrier densities were close to $10^{18}$ $\mathrm{cm}^{-3}$ for both tested precursors' orders.

Despite producing CZTS with, apparently, good crystal quality, this growth method still presents considerable surface irregularity problems. Further work must be carried out in order to improve that aspect. The effect of the sulfurization working pressure must be studied. Another related issue that must be investigated is the effect of the roughness of the individual metallic precursors on the final CZTS surface roughness.

The results of this work point to the possibility of the KCN treatment also removing SnS besides the $\mathrm{Cu}_{2-\mathrm{x}} \mathrm{S}$ phases. Further systematic work will be performed to clarify that possibility and presented elsewhere.

\section{Acknowledgements}

P.M.P. Salomé acknowledges the financial support by Fundação para a Ciência e Tecnologia, Portugal (FCT), through a PhD grant number SFRH/BD/ 29881/2006. FCT is also acknowledged for the financial support of the national electronic microscopy network, whose services we have used, through the grant REDE/1509/RME/2005.

\section{References}

[1] J.M. Raulot, C. Domain , J.F. Guillemoles, Journal of Physics and Chemistry of Solids, 66 (2005), 2019-2023.

[2] T M Friedlmeier, H Dittrich and H W Schock, The 11th Conference on Ternary and Multinary Compounds, ICTMC-11, Salford, 8-12 September, (1997), p. 345.

[3] H. Katagiri, K. Saitoh, T. Washio, H. Shinohara, T. Kurumadani, S. Miyajima, Solar Energy Materials and Solar Cells, 65, Issues 1-4, (2001), 141-148.

[4] T. Tanaka, D. Kawasaki, M. Nishio, Q. Guo, H. Ogawa, Phys. Stat. sol. (c), 3, No. 8, (2006), 2844-2847.

[5] A. Weber, H. Krauth, S. Perlt, B. Schubert, I. Kotschau, S. Schorr, H.W. Schock, Thin Solid Films, 517 (2009), 2524-2526.

[6] KK. Jimbo, R. Kimura, T. Kamimura, S. Yamada, W. Maw, H. Araki, K. Oishi, H. Katagiri, Thin Solid Films, 515, Issue 15, (2007), 5997-5999.

[7] T. Todorov, M. Kita, J. Carda, P. Escribano, Thin Solid Films, 517, (2009), 2541-2544.

[8] K. Tanaka, N. Moritake, H. Uchiki, Solar Energy Materials and Solar Cells, 91, Issue 13, (2007), 1199-1201.

[9] N. Nakayama and K. Ito, Applied Surface Science, 92, (1996), 171-175. 
[10] N. Kamoun, H. Bouzouita, B. Rezig, Thin Solid Films, 515, Issue 15, (2007), 5949-5952.

[11] R. Schurr, A. Holzing, S. Jost, R. Hock, T. Voß, J. Schulze, A. Kirbs, A. Ennaoui, M. LuxSteiner, A. Weber, I. Kotschau, H.-W. Schock, Thin Solid Films, 517, (2009), 2465-2468.

[12] J.J. Scragg, P.J. Dale, L.M. Peter, Thin Solid Films, 517, (2009), 2481-2484.

[13] H. Katagiri, K. Jimbo, S. Yamada, T. Kamimura, W. S. Maw, T. Fukano, T. Ito, and T. Motohiro, Appl. Phys. Express 1, (2008), 041201.

[14] P.A. Fernandes, P.M.P. Salome, A.F. da Cunha, Thin Solid Films, 517, (2009), 2519-2523.

[15] John H. Scofield, A. Duda, D. Albin, B. L. Ballard, P. K. Predecki, Thin Solid Films, 260, Issue 1, (1995), 26-31.

[16] CE Kril, R Birringer, Philosophical Magazine A, 77, Issue 3, (1998), 621 - 640.

[17] M. Altosaar, J. Raudoja, K. Timmo, M. Danilson, M. Grossberg, J. Krustok, and E. Mellikov, phys. stat. sol. (a), 205 No. 1, (2008), 167-170.

[18] Carolyn G. Munce, Gretel K. Parker, Stephen A. Holt, Gregory A. Hopea, Colloids and Surfaces A: Physicochem., Eng. Aspects, 295, (2007), 152-158.

[19] G. Gouadec and P. Colomban, J. Raman Spectrosc., 38, (2007), 598-603.

[20] Karthik Shankar, Kong Chhay Tep, Gopal K. Mor and Craig A Grimes, J. Phys. D: Appl. Phys., 39 (2006) 2361-2366.

[21] I. Grozdanov, M. Najdoski, J. Solid State Chem., 114 (1995), 469-475.

[22] J. Hilbrand, R. D. Gold, RCA Laboratories, Princeton, N.J, (1960).

[23] T. Tanaka, T. Nagatomo, D. Kawasaki, M. Nishio, Q. Guo, A. Wakahara, A. Yoshida, H. Ogawa, J. Phys. Chem. Solids, 66 (2005), 1978-1981. 